\title{
REVISED
}

\section{Evaluation of two multi-locus sequence typing schemes for commensal Escherichia coli from dairy cattle in Washington State}

Sara Ahmed ${ }^{\mathrm{a}}$, Thomas E. Besser ${ }^{\mathrm{b}}$, Douglas R. Call ${ }^{\mathrm{a}}$, Scott J. Weissman ${ }^{\mathrm{c}}$, Lisa P. Jones ${ }^{\mathrm{a}}$, Margaret

\author{
A. Davis ${ }^{\mathrm{a}, *}$ \\ ${ }^{a}$ Paul G. Allen School for Global Animal Health, WSU, Pullman, WA, USA, ${ }^{b}$ Veterinary \\ Microbiology and Pathology, College of Veterinary Medicine, WSU, Pullman, WA, USA, \\ ${ }^{\mathrm{c}}$ Seattle Children's Research Institute, Seattle, WA, USA.
}

Running head: Evaluating CH Typing for commensal E. coli

*Corresponding author:

Dr. Margaret Davis, $\mathrm{PhD}$

Paul G. Allen School for Global Animal Health

Washington State University

230 SE Ott Road

Pullman, WA 99164-7090

Tel: 509-335-3831; email: madavis@vetmed.wsu.edu 
1

2 Multi-locus sequence typing (MLST) is a useful system for phylogenetic and epidemiological

3 studies of multidrug-resistant E. coli. Most studies utilize a seven-locus MLST, but an alternate

4 two-locus typing method ( $\mathrm{fumC}$ and $\mathrm{fimH}$; $\mathrm{CH}$ typing) has been proposed that may offer a

5 similar degree of discrimination at lower cost. Herein, we compare $\mathrm{CH}$ typing to the standard

6 seven-locus method for typing commensal E. coli isolates from dairy cattle. In addition, we

7 evaluated alternative combinations of eight loci to identify combinations that maximize

8 discrimination and congruence with standard seven-locus MLST among commensal E. coli while

9 minimizing cost. We also compared both methods when used for typing uropathogenic E. coli

10 (UPEC). $\mathrm{CH}$ typing was less discriminatory for commensal E. coli than the standard seven-locus

11 method (Simpson's Index of Diversity $=0.933$ [0.902-0.964] and 0.97 [0.96-0.979],

12 respectively). Combining fim $H$ with housekeeping gene loci improved discriminatory power for

13 commensal E. coli from cattle but resulted in poor congruence with MLST. We found that a

14 four-locus typing method including the housekeeping genes adk, purA, gyrB and $\operatorname{rec} A$ could be

15 used to minimize cost without sacrificing discriminatory power or congruence with Achtman

16 seven-locus MLST when typing commensal E. coli.

\section{Abbreviations}

$18 \mathrm{CH}$ typing, (fum $\mathrm{C}$-fim $H$ ) typing; ESBL, extended-spectrum $\beta$-lactamase; MLST, multi-locus 19 sequence typing; UPEC, uropathogenic E. coli.

20 Keywords: MLST; CH typing; fimH; housekeeping genes; E. coli 
23 Pathogenic Escherichia coli can cause extraintestinal infections, including urinary tract

24 infections, bloodstream infections, and meningitis (Kaper et al., 2004). Community and hospital-

25 acquired ESBL-producing $E$. coli are increasingly frequent; in addition to resistance to $\beta$ -

26 lactams, these pathogens are also resistant to other classes of antimicrobial drugs (Ben-Ami et

27 al., 2009; Doi et al., 2010; Pitout and Laupland, 2008; Toval et al., 2014). CTX-M enzymes are

28 the most prevalent ESBLs worldwide (Canton and Coque, 2006; Canton et al., 2012). Recently,

29 relatively high prevalences of commensal E. coli carrying bla $a_{\text {CTX-M }}$ have been detected in U.S.

30 livestock populations (Davis et al., 2015; Mollenkopf et al., 2012). To understand the role of

31 bacterial dissemination in population-level changes in antimicrobial resistance, and to discover

32 the sources and transmission routes for bla $a_{\mathrm{CTX}-\mathrm{M}}-$ carrying commensal E. coli strains isolated

33 from different farms, an effective and reliable strain-typing method is needed.

34 Typing methods that are based on DNA sequence variation of slowly evolving housekeeping

35 genes have been used for epidemiological studies and to determine evolutionary relationships

36 among E. coli, including ESBL-producing strains (Cooper and Feil, 2004; Maiden, 2006; Urwin

37 and Maiden, 2003). The Achtman seven-locus scheme is the most frequently used (Clermont et

38 al., 2015; Wirth et al., 2006). Analysis of sequence types and clonal complexes (closely related

39 sequence types) enables identification of a specific clone or clones that are associated with

40 certain bla $a_{\text {СтX-M }}$ genes. For example, E. coli $\mathrm{ST} 131$ is a clonal group of pathogenic $E$. coli that is

41 associated with bla $a_{\mathrm{CTX}-\mathrm{M}-15}$ (Livermore, 2012; Nicolas-Chanoine et al., 2008; Peirano and Pitout,

42 2010). Depending on the number of loci included in the assay, conventional MLST assays can be

43 expensive and may lack discriminatory power because of the slow accumulation of genetic

44 variation across housekeeping genes (Overdevest et al., 2012). 
45 A two-locus typing scheme was developed for clinical E. coli isolates based on a housekeeping

46 gene $($ fum $C)$ and a virulence gene $($ fim $H)$. This scheme displayed a greater discriminatory power

47 compared to seven-locus MLST and was able to clearly differentiate clinical E. coli isolates at a

48 lower cost (Weissman et al., 2012). We evaluated the suitability of the $\mathrm{CH}$ typing scheme as a

49 tool to discriminate among CTX-M-carrying commensal E. coli from cattle, and compared the

50 discriminatory power of different combinations of loci, as well as their correspondence with the

51 Achtman seven-locus scheme, for assessing diversity and clonal relationships among commensal

52 E. coli from cattle.

\section{2. Materials and methods}

55 2.1. Bacterial isolates:

56 We selected 150 E. coli isolates that were obtained during a previous study of $E$. coli carrying 57 bla $a_{\text {СТХ-м }}$ on dairy farms in Washington State (Davis et al., 2015). E. coli isolates were archived at $-80^{\circ} \mathrm{C}$ in buffered glycerol for long-term storage. The presence of bla $a_{\text {СтХ-м }}$ was determined

59 using published PCR protocols (Edelstein et al., 2003; Mollenkopf et al., 2012). For the current

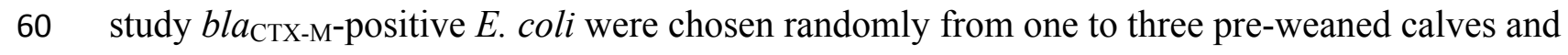
61 adult cows on each of 27 farms (total $\mathrm{n}=75$ ). Isolates that were $b l a_{\mathrm{CTX}-\mathrm{M}}$-negative were available

62 from 18 of those 27 farms and from each of those we chose one to six isolates randomly from 63 pre-weaned calves and adult cows. Randomization was performed using the RAND function in 64 Microsoft Excel (Redmond, WA, USA). The result was a set of 150 isolates including 75 with

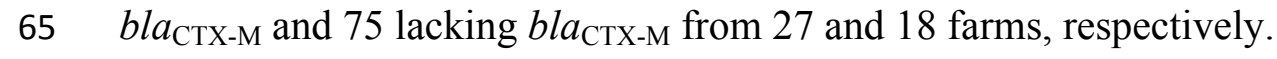

66 To determine whether the combination of MLST loci optimized for commensal E. coli from

67 cattle would be suitable for clinical E. coli, we used 27 multidrug resistant (MDR) E. coli 
68 isolates associated with urinary tract infections in dogs hospitalized at the Washington State

69 University Veterinary Teaching Hospital (Pullman, Washington, USA) between October 2009

70 and October 2013. This analysis also incorporated the MLST and fimH sequence data for 23

71 UPEC strains (6 dog and 17 human strains) from published data (Weissman et al., 2012).

72 2.2. Nucleic acid extraction:

73 Single colonies were inoculated into brain heart infusion (BHI) broth (3 ml) and these cultures

74 were incubated overnight at $37^{\circ} \mathrm{C}$. Genomic DNA was isolated using Qiagen DNeasy blood and

75 tissue kit according to manufacturer's instructions (Qiagen Sciences Inc., Germantown, MA). All

76 DNA preparations were stored at $4^{\circ} \mathrm{C}$.

77 2.3. MLST

78 Seven-locus MLST was performed using published criteria and primers (Wirth et al., 2006).

79 Internal fragments of seven housekeeping genes ( $a d k$, fum $C, \operatorname{gyr} B, i c d, m d h, p u r A, \operatorname{rec} A)$ were

80 amplified in individual reactions and amplification products were submitted to a commercial

81 sequencing service (Functional Biosciences, Inc, Madison, WI). The same primers were used for

82 amplification and bi-directional sequencing [see

83 http://mlst.warwick.ac.uk/mlst/dbs/Ecoli/documents/primersColi_html (Wirth et al., 2006)]. The

84 raw trace files were evaluated and assembled into contigs using BioNumerics v. 6.6 (Applied

85 Maths, Sint-Martens-Latem, Belgium). The allelic profile for each isolate was determined using

86 the BioNumerics MLST Plug-in in accordance with the Achtman scheme available at

87 http://mlst.warwick.ac.uk/mlst/dbs/Ecoli. Sequence traces of novel alleles were submitted to the

88 database curator for new allele and sequence type (ST) assignment. Isolates were classified as 
89 the same ST if their alleles were identical at all seven loci. For the purposes of this report, the

90 term "MLST" will be used to denote the Achtman seven-locus scheme.

91 2.4. fim $H$ sequencing and $\mathrm{CH}$ typing analysis

92 fimH amplification and sequencing was done as previously published (Weissman et al., 2012)

93 using the primers: fimH-F,CACTCAGGGAACCATTCAGGC; fimH-R,

94 CTTATTGATAAACAAAAGTCAC. Cycling conditions for all reactions consisted of 1 cycle of

$9594^{\circ} \mathrm{C}$ for $5 \mathrm{~min}$, followed by 30 cycles of $94^{\circ} \mathrm{C}$ for $30 \mathrm{~s}, 57^{\circ} \mathrm{C}$ for $15 \mathrm{~s}$, and $72^{\circ} \mathrm{C}$ for $1 \mathrm{~min}$.

96 Contigs were assembled using Sequencher 5.0 (Gene Codes Corporation, Ann Arbor, MI). Allele

97 assignments for fimH were determined by one of the coauthors (SJW). In cases when the PCR

98 results were negative for the expected 975 bp product for $f i m H$, the allele was assigned allele

99 number 0 . Sequence traces of novel fumC alleles were submitted to the MLST database curator

100 for new allele assignment. The combination of fum $\mathrm{C}$ and $\mathrm{fim} H$ allele designations were used as

101 the $\mathrm{CH}$ "type."

$102 \quad$ 2.5. Discriminatory power analyses and clustering comparison coefficients

103 The discriminatory power of each typing method was evaluated using Simpson's index of

104 diversity ( $D$-index). The $D$-index is a measure of the probability that two randomly sampled

105 isolates from a population belong to different types. The index ranges between 0 and 1 and a

106 value $\geq 0.95$ is interpreted to mean that the method is suitable for molecular typing (van Belkum

107 et al., 2007). We used the online tool at www.comparingpartitions.info to calculate the

108 Simpson's index of diversity (Simpson, 1949). 
109 The Adjusted Rand $(A R)$ and Adjusted Wallace $(A W)$ coefficients were used to assess the 110 agreement between the different typing methods. The $A R$ coefficient is an estimate of the overall 111 concordance between two typing methods after eliminating the degree of concordance that is 112 attributable to chance. The $A W$ coefficient measures how well each method predicts the type 113 assignment of the other method, accounting for the amount of agreement expected by chance.

114 We also used the online tool at www.comparingpartitions.info to calculate these two coefficients 115 (Carrico et al., 2006; Severiano et al., 2011). In total we evaluated all possible combinations of

116 eight loci $\left(2^{8}-1\right.$, or 255 combinations of loci).

\section{3. Results}

118 3.1. Evaluation of the $\mathrm{CH}$ typing method for use on commensal E. coli.

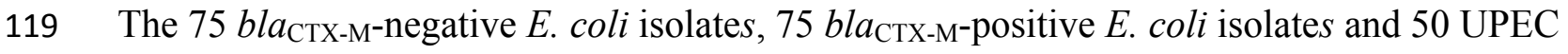
120 strains were partitioned into 49, 26, and 27 MLST profiles (STs) and 48, 24, and 34 CH types 121 (CHTs), respectively. 


\begin{tabular}{|c|c|c|c|c|c|}
\hline & & $\begin{array}{l}\text { No. of } \\
\text { types }\end{array}$ & $\begin{array}{c}\text { Simpson's index } \\
\text { of diversity } D^{\mathrm{a}}\end{array}$ & $\begin{array}{l}\text { Adjusted Rand } \\
\text { coefficient }^{\mathbf{b}}\end{array}$ & $\begin{array}{c}\text { Adjusted Wallace } \\
\text { coefficient }^{\mathbf{c}}\end{array}$ \\
\hline \multirow{2}{*}{$\begin{array}{l}\text { bla } a_{\mathrm{CTX}-\mathrm{M}-\text { negative }} \\
\text { E. coli isolates } \\
\mathbf{n}=\mathbf{7 5}\end{array}$} & MLST & 49 & $\begin{array}{c}0.976 \\
(0.960-0.993)\end{array}$ & \multirow{2}{*}{$\begin{array}{c}0.308 \\
(0.146-0.465)\end{array}$} & $\begin{array}{c}0.274 \\
(0.156-0.392)\end{array}$ \\
\hline & $\begin{array}{c}\text { CH } \\
\text { typing }\end{array}$ & 48 & $\begin{array}{c}0.981 \\
(0.970-0.992)\end{array}$ & & $\begin{array}{c}0.350 \\
(0.207-0.493)\end{array}$ \\
\hline \multirow{2}{*}{$\begin{array}{l}\text { bla }_{\mathrm{CTX}-\mathrm{M}-\text { positive }} \\
\text { E. coli isolates } \\
\mathbf{n}=\mathbf{7 5}\end{array}$} & MLST & 26 & $\begin{array}{c}0.94 \\
(0.918-0.962)\end{array}$ & \multirow{2}{*}{$\begin{array}{c}0.416 \\
(0.269-0.554)\end{array}$} & $\begin{array}{c}0.849 \\
(0.776-0.922)\end{array}$ \\
\hline & $\begin{array}{c}\mathrm{CH} \\
\text { typing }\end{array}$ & 24 & $\begin{array}{c}0.835 \\
(0.757-0.913)\end{array}$ & & $\begin{array}{c}0.275 \\
(0.173-0.378)\end{array}$ \\
\hline \multirow{2}{*}{$\begin{array}{l}\text { UPEC } \\
\mathbf{n}=\mathbf{5 0}\end{array}$} & MLST & 27 & $\begin{array}{c}0.957 \\
(0.933-0.981)\end{array}$ & \multirow{2}{*}{$\begin{array}{c}0.664 \\
(0.446-0.905)\end{array}$} & $\begin{array}{c}0.516 \\
(0.332-0.701)\end{array}$ \\
\hline & $\begin{array}{c}\text { CH } \\
\text { typing }\end{array}$ & 34 & $\begin{array}{c}0.976 \\
(0.959-0.992)\end{array}$ & & $\begin{array}{c}0.93 \\
(0.865-0.996)\end{array}$ \\
\hline
\end{tabular}

\footnotetext{
${ }^{\mathrm{a}}$ The probability that two strains sampled randomly from a population belong to two different types ( $95 \%$ confidence interval).

${ }^{\mathrm{b}}$ The overall concordance of two methods taking into account that the agreement between partitions could arise by chance alone ( $95 \%$ confidence interval).

${ }^{\mathrm{c}} A W_{M L S T \rightarrow C H}$ (MLST rows) is the probability that two strains are classified together using $\mathrm{CH}$ typing if they have been classified together using MLST; $\mathrm{AW}_{\mathrm{CH} \rightarrow M L S T}$ ( $\mathrm{CH}$ rows) is the probability that two strains are classified together using MLST if they have been classified together using $\mathrm{CH}$ typing (95\% confidence interval).
} 
130 The Simpson's index of diversity $(D)$ for MLST and CH typing were equivalent for bla $a_{\mathrm{CTX}_{\mathrm{M}} \mathrm{M}^{-}}$

131

132

133

134

135

136

137

138

139

140

141

142

143

144

145

146

147

148

149

150 151 isolates $(n=150)$.

negative E. coli isolates and for UPEC strains. In contrast, the discriminatory power of MLST

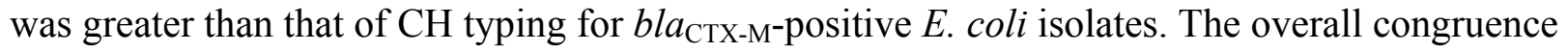

between the two methods, as measured by the $A R$ coefficient, was low for both $b l a_{\mathrm{CTX}-\mathrm{M} \text {-negative }}$

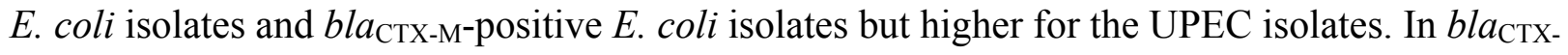

$\mathrm{M}^{-}$negative $E$. coli isolates, Wallace indices indicated that MLST and CH typing were each non-

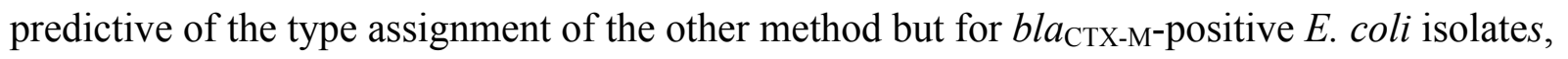

MLST assignments were more predictive of $\mathrm{CH}$ typing assignments than the other way around.

This was the reverse for UPEC for which $\mathrm{CH}$ typing had higher ability to predict MLST

assignments. Thus, $\mathrm{CH}$ typing was more discriminatory and concordant with MLST when used

to study UPEC, while MLST was equally or more discriminatory than $\mathrm{CH}$ typing when used on

commensal E. coli isolates from cattle. For the commensal E. coli, there was a significant

difference between the $A W_{M L S T \rightarrow C H}$ for $b l a_{\mathrm{CTX}-\mathrm{M}-\text { positive and -negative } E \text {. coli: MLST had a }}$

higher ability to predict $\mathrm{CH}$ typing assignments for the latter group (Table 1).

3.2. Determining the optimal combination of loci for typing commensal E. coli.

We evaluated individual loci as well as all combinations of the eight loci to determine their discriminatory power and agreement with MLST. For both commensal E. coli and UPEC, gyrB and fim $H$ were the two most variable loci and had the highest $D$ values. Also, gyr $B$ demonstrated the best congruence with MLST profiles measured by the Adjusted Rand coefficients (Table 2).

To evaluate combinations of two to eight loci, we combined the bla $a_{\mathrm{CTX}-\mathrm{M}}$-positive $(\mathrm{n}=75)$ and

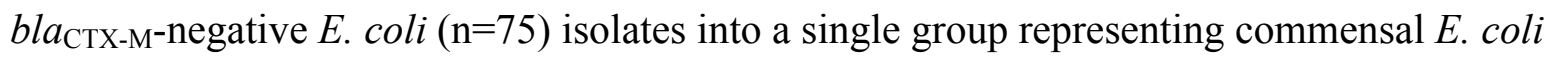


153 individual locus for cattle commensal E. coli isolates and UPEC isolates.

\begin{tabular}{|c|c|c|c|c|c|c|c|c|c|}
\hline & \multicolumn{3}{|c|}{ No. of types found } & \multicolumn{4}{|c|}{ Simpson's index of diversity D $(95 \% \mathrm{CI})$} & \multicolumn{2}{|c|}{$\begin{array}{l}\text { Adjusted Rand Coefficient } \\
\qquad(95 \% \mathrm{CI})\end{array}$} \\
\hline & \multicolumn{2}{|c|}{ Commensal E. coli } & \multirow{3}{*}{$\begin{array}{l}\text { UPEC } \\
(n=50)\end{array}$} & \multicolumn{2}{|c|}{ Commensal E. coli } & \multirow{3}{*}{$\begin{array}{l}\text { UPEC } \\
(\mathrm{n}=50)\end{array}$} & \multicolumn{2}{|c|}{ Commensal E. coli } & \multirow{3}{*}{$\begin{array}{l}\text { UPEC } \\
(n=50)\end{array}$} \\
\hline & $b l a_{\mathrm{CTX}-\mathrm{M}^{+}}$ & $b l a_{\mathrm{CTX}^{-\mathrm{M}^{-}}}$ & & bla $_{\text {СтХ-м }}+$ & $b l a_{\mathrm{CTX}_{\mathrm{M}}}-$ & & bla $_{\text {СтХ-м }}+$ & $b l a_{\mathrm{CTX}_{-}}^{-}$ & \\
\hline & $(n=75)$ & $(n=75)$ & & $(n=75)$ & $(n=75)$ & & $(n=75)$ & $(n=75)$ & \\
\hline fimH & 18 & 31 & 27 & $\begin{array}{c}0.726 \\
(0.621-0.831)\end{array}$ & $\begin{array}{c}0.92 \\
(0.879-0.960)\end{array}$ & $\begin{array}{c}0.952 \\
(0.924-0.980)\end{array}$ & $\begin{array}{c}0.24 \\
(0.142-0.335)\end{array}$ & $\begin{array}{c}0.098 \\
(0.011-0.180)\end{array}$ & $\begin{array}{c}0.476 \\
(0.172-0.781)\end{array}$ \\
\hline$g y r B$ & 13 & 18 & 19 & $\begin{array}{c}0.84 \\
(0.801-0.880)\end{array}$ & $\begin{array}{c}0.85 \\
(0.786-0.913)\end{array}$ & $\begin{array}{c}0.922 \\
(0.885-0.958)\end{array}$ & $\begin{array}{c}0.504 \\
(0.327-0.679)\end{array}$ & $\begin{array}{c}0.242 \\
(0.125-0.365)\end{array}$ & $\begin{array}{c}0.694 \\
(0.452-0.939)\end{array}$ \\
\hline$i c d$ & 12 & 13 & 12 & $\begin{array}{c}0.743 \\
(0.666-0.819)\end{array}$ & $\begin{array}{c}0.841 \\
(0.804-0.878)\end{array}$ & $\begin{array}{c}0.889 \\
(0.854-0.924)\end{array}$ & $\begin{array}{c}0.312 \\
(0.215-0.407)\end{array}$ & $\begin{array}{c}0.242 \\
(0.125-0.365)\end{array}$ & $\begin{array}{c}0.532 \\
(0.339-0.735)\end{array}$ \\
\hline fumC & 12 & 18 & 21 & $\begin{array}{c}0.733 \\
(0.651-0.814)\end{array}$ & $\begin{array}{c}0.823 \\
(0.758-0.888)\end{array}$ & $\begin{array}{c}0.949 \\
(0.927-0.970)\end{array}$ & $\begin{array}{c}0.299 \\
(0.200-0.394)\end{array}$ & $\begin{array}{c}0.203 \\
(0.057-0.344)\end{array}$ & $\begin{array}{c}0.91 \\
(0.797-1.000)\end{array}$ \\
\hline$m d h$ & 9 & 10 & 14 & $\begin{array}{c}0.637 \\
(0.528-0.747)\end{array}$ & $\begin{array}{c}0.835 \\
(0.792-0.878)\end{array}$ & $\begin{array}{c}0.918 \\
(0.896-0.941)\end{array}$ & $\begin{array}{c}0.202 \\
(0.119-0.282)\end{array}$ & $\begin{array}{c}0.22 \\
(0.097-0.350)\end{array}$ & $\begin{array}{c}0.674 \\
(0.449-0.919)\end{array}$ \\
\hline recA & 9 & 11 & 14 & 0.667 & 0.793 & 0.914 & 0.227 & 0.171 & 0.651 \\
\hline
\end{tabular}




\begin{tabular}{|c|c|c|c|c|c|c|c|c|c|}
\hline & & & & $(0.570-0.764)$ & $(0.744-0.842)$ & $(0.889-0.939)$ & $(0.145-0.306)$ & $(0.063-0.281)$ & $(0.448-0.872)$ \\
\hline \multirow[t]{2}{*}{$a d k$} & 10 & 12 & 18 & 0.641 & 0.584 & 0.932 & 0.205 & 0.066 & 0.767 \\
\hline & & & & $(0.575-0.707)$ & $(0.461-0.707)$ & $(0.909-0.955)$ & $(0.136-0.275)$ & $(0.001-0.125)$ & $(0.530-1.000)$ \\
\hline \multirow[t]{2}{*}{ purA } & 12 & 13 & 14 & 0.545 & 0.578 & 0.897 & 0.143 & 0.065 & 0.566 \\
\hline & & & & $(0.411-0.679)$ & $(0.448-0.708)$ & $(0.855-0.939)$ & $(0.067-0.213)$ & $(0.017-0.112)$ & $(0.338-0.796)$ \\
\hline
\end{tabular}

154

155 
156 For typing commensal E. coli, maximum discriminatory power did not significantly increase 157 with the addition of $>2$ loci, and the maximum Adjusted Rand coefficient achievable did not 158 significantly increase with $>4$ loci (Figures S1-S3). For commensal E. coli, none of the 159 combinations of loci that maximized congruence with MLST included the fimH gene (Table 3, 160 Figures S1-S3), and the four loci that would maximize both congruence with MLST and 161 discriminatory power were $a d k$, purA, gyrB, and $\operatorname{rec} A$ (Table 3, Figure S1).

162 3.3. Distribution of CH Types and MLST sequence types among commensal E. coli and UPEC.

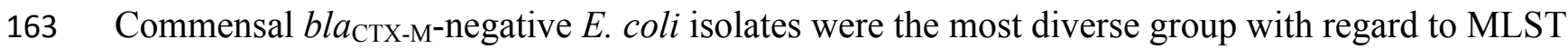
164 types, each of which included $\leq 3 \mathrm{CH}$ types, except for ST58 and ST10; and, as would follow, 165 few $\mathrm{CH}$ types included more than one MLST type among bla $\mathrm{CTX}_{\mathrm{M}}$-negative $E$. coli isolates.

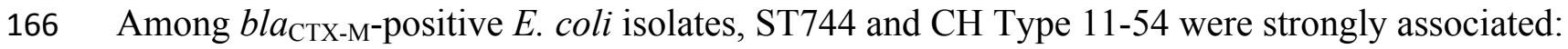
167 of 29 CH Type 11-54 isolates, 12 were ST744 and all ST744 were CH Type 11-54. CH Type 1116854 also included five other MLST types. Among UPEC isolates, ST groups routinely included 169 multiple CH Types, but only CH Type 35-27 included more than one MLST, ST69 and ST597 170 (Supplemental Table 1). 
171 Table 3. Number of types found, $D$ values and Adjusted Rand Coefficient with MLST of different combinations of two to eight gene

172 loci chosen to confer maximum congruence with MLST (Adjusted Rand Coefficient) for 150 commensal E. coli isolates. Results from

17350 UPEC isolates are presented for comparison.

\begin{tabular}{|c|c|c|c|c|c|c|}
\hline \multirow[b]{2}{*}{ Loci } & \multirow[b]{2}{*}{$\begin{array}{l}\text { Commensal } \\
\qquad(\mathrm{n}=150)\end{array}$} & \multirow[b]{2}{*}{$\begin{array}{l}\text { UPEC } \\
(\mathrm{n}=50)\end{array}$} & \multicolumn{2}{|c|}{$\begin{array}{c}\text { Simpson's } D \\
(95 \% \mathrm{CI})\end{array}$} & \multicolumn{2}{|c|}{$\begin{array}{c}\text { Adjusted Rand Coefficient }^{a} \\
(95 \% \text { CI })\end{array}$} \\
\hline & & & $\begin{array}{l}\text { Commensal } \\
\qquad(\mathrm{n}=150)\end{array}$ & $\begin{array}{l}\text { UPEC } \\
(n=50)\end{array}$ & $\begin{array}{l}\text { Commensal } \\
\qquad(n=150)\end{array}$ & $\begin{array}{l}\text { UPEC } \\
(n=50)\end{array}$ \\
\hline gyrB+icd & 44 & 24 & $\begin{array}{c}0.942 \\
(0.925-0.960)\end{array}$ & $\begin{array}{c}0.951 \\
(0.928-0.975)\end{array}$ & $\begin{array}{c}0.676 \\
(0.553-0.797)\end{array}$ & $\begin{array}{c}0.935 \\
(0.839-1.000)\end{array}$ \\
\hline$a d k+g y r B+i c d$ & 47 & 27 & $\begin{array}{c}0.957 \\
(0.946-0.968)\end{array}$ & $\begin{array}{c}0.957(0.933- \\
0.981)\end{array}$ & $\begin{array}{c}0.818 \\
(0.725-0.914)\end{array}$ & $\begin{array}{c}1.000 \\
(1.000-1.000)\end{array}$ \\
\hline$a d k+p u r A+g y r B+r e c A$ & 58 & 27 & $\begin{array}{c}0.967 \\
(0.957-0.976)\end{array}$ & $\begin{array}{c}0.957 \\
(0.933-0.981)\end{array}$ & $\begin{array}{c}0.955 \\
(0.903-1.000)\end{array}$ & $\begin{array}{c}1.000 \\
(1.000-1.000)\end{array}$ \\
\hline$a d k+f u m C+p u r A+g y r B+\operatorname{rec} A$ & 65 & 27 & $\begin{array}{c}0.97 \\
(0.960-0.979)\end{array}$ & $\begin{array}{c}0.957 \\
(0.933-0.981)\end{array}$ & $\begin{array}{c}1.000 \\
(1.000-1.000)\end{array}$ & $\begin{array}{c}1.000 \\
(1.000-1.000)\end{array}$ \\
\hline$a d k+f u m C+g y r B+p u r A+i c d+r e c A$ & 65 & 27 & 0.97 & 0.957 & 1.000 & 1.000 \\
\hline
\end{tabular}




\begin{tabular}{|c|c|c|c|c|c|c|}
\hline & & & $(0.960-0.979)$ & $(0.933-0.981)$ & $(1.000-1.000)$ & $(1.000-1.000)$ \\
\hline$a d k+f u m C+i c d+m d h+p u r A+g y r B+r e c A^{b}$ & 65 & 27 & $\begin{array}{c}0.97 \\
(0.960-0.979)\end{array}$ & $\begin{array}{c}0.957 \\
(0.933-0.981)\end{array}$ & --- & --- \\
\hline fim $H+a d k+f u m C+p u r A+g y r B+i c d+r e c A+m d h$ & 85 & 35 & $\begin{array}{c}0.981 \\
(0.973-0.989)\end{array}$ & $\begin{array}{c}0.977 \\
(0.961-0.994)\end{array}$ & $\begin{array}{c}0.759 \\
(0.627-0.898)\end{array}$ & $\begin{array}{c}0.682 \\
(0.462-0.922)\end{array}$ \\
\hline CH Typing & 65 & 34 & $\begin{array}{c}0.933 \\
(0.902-0.964)\end{array}$ & $\begin{array}{c}0.976 \\
(0.959-0.992)\end{array}$ & $\begin{array}{c}0.36 \\
(0.262-0.454)\end{array}$ & $\begin{array}{c}0.664 \\
(0.446-0.905)\end{array}$ \\
\hline
\end{tabular}

174

${ }^{a}$ Estimate of overall congruence with MLST

$175 \quad{ }^{b}$ Achtman seven MLST housekeeping genes 


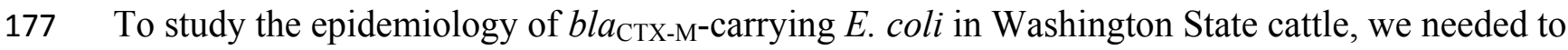
178 genotype as many isolates as possible with maximum validity and genetic resolution, but at 179 minimal cost. A two-locus method utilizing fimH and fumC sequences (Weissman et al., 2012) 180 had better discriminatory power than MLST and correlated well with MLST when used on a 181 diverse isolate collection; for studies involving hundreds of bacterial isolates, the cost and labor 182 savings with a two-locus method would be significant. Nevertheless, when used on cattle 183 commensal E. coli, the discriminatory power of $\mathrm{CH}$ typing was lower than when used in UPEC, 184 and the congruence with MLST was poor. We concluded that $\mathrm{CH}$ Typing was not an adequate 185 substitute for MLST for typing cattle commensal E. coli. Combining fimH allele information with subsets of the seven housekeeping gene loci improved discriminatory power, but decreased 187 congruence with MLST (Figures S1-S3). Our analysis of all possible combinations of fimH, 188 $a d k$, fum $C, \operatorname{gyr} B, i c d, m d h$, purA, and $\operatorname{rec} A$ alleles on commensal E. coli from cattle indicated that costs of typing could be minimized without significantly sacrificing discriminatory power by using the four loci adk, purA, gyrB and $\operatorname{rec} A$ (Table 3, Figures S1-S3).

In contrast with commensal E. coli, increasing the number of housekeeping gene loci did 192 not add to the discriminatory power or improve congruence with MLST for UPEC isolates 193 (Table 3). The uniformity of $D$ values for different numbers of loci in UPEC suggests a close 194 association between fimH alleles and MLST type among UPEC, which is consistent with our 195 findings that ST groups routinely encompassed multiple $f i m H$ alleles, but only one $\mathrm{CH}$ Type 196 mapped to more than one ST (35-27 with ST69 and ST597; Supplemental Table). Housekeeping

197 genes are under neutral or stabilizing selection pressures so that genetic variation arises at a 198 relatively low rate (Dan et al., 2014; Jolley and Maiden, 2014), while genes that experience 
199 positive selection pressure, such as $f i m H$, evolve more rapidly resulting in greater genetic 200 variation over similar time periods and thus provide greater potential discriminatory power when used to compare strains (Dan et al., 2014; Jolley and Maiden, 2014; Schwartz et al., 2013; Zhang 202 et al., 2014). Point mutations resulting in pathoadaptive amino acid substitutions in fimH of 203 UPEC have been identified in multiple studies (Paul et al., 2013; Schwartz et al., 2013;

204 Sokurenko et al., 1998; Weissman et al., 2006). This could explain the finding that UPEC have 205 206 discriminatory ability of CH typing for UPEC strains (Weissman et al., 2012).

The greatest limitation to this study is the potential lack of generalizability to other $E$. coli populations. Our results for commensal isolates may have been biased by the higher proportion

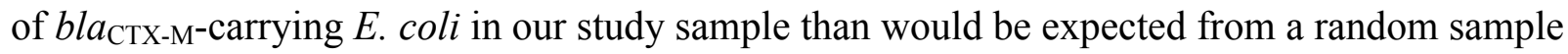
of commensal cattle fecal E. coli. Most if not all studies of E. coli molecular epidemiology target a specific sub-population of this ubiquitous and highly diverse species so it would be possible to evaluate our four-locus method for given a sample of isolates from other host sources, geographic location, environmental matrix, and selection criteria. However, our purpose was not to provide a recommendation for MLST typing of all E. coli, but to evaluate $\mathrm{CH}$ typing for a cattle commensal E. coli and to describe a process for maximizing typing value while minimizing cost. Whole-genome sequencing (WGS) is currently becoming more accessible for use on large numbers of bacterial isolates and in the long term may become a standard for epidemiology research as well as outbreak investigation, but the availability of curated, online international databases for MLST (such as the MLST databases at the University of Warwick) currently provide context for broad comparisons that is not yet available for WGS (Clermont et al., 2015; Gilmour et al., 2013). 
222 5. Conclusion

223 This study demonstrated that $\mathrm{CH}$ typing is less suitable than MLST for typing commensal

$224 E$. coli from cattle. Our findings also suggest that costs of genetic typing of hundreds of field $E$.

225 coli isolates could be minimized without sacrificing either discriminatory power or

226 correspondence with MLST by using only four loci, adk, $\operatorname{pur} A, \operatorname{gyr} B$ and $\operatorname{rec} A$.

227 Acknowledgments

228 This project was supported by funding from National Integrated Food Safety Initiative (NIFSI)

229 Grant no. 2010-51110-21131 from the USDA National Institute of Food and Agriculture. 


\section{References}

Ben-Ami, R., Rodriguez-Bano, J., Arslan, H., Pitout, J.D., Quentin, C., Calbo, E.S., Azap, O.K., Arpin, C., Pascual, A., Livermore, D.M., Garau, J., Carmeli, Y., 2009. A multinational survey of risk factors for infection with extended-spectrum beta-lactamase-producing enterobacteriaceae in nonhospitalized patients. Clin Infect Dis. 49, 682-690.

Canton, R., Coque, T.M., 2006. The CTX-M beta-lactamase pandemic. Curr Opin Microbiol. 9, 466-475.

Canton, R., Gonzalez-Alba, J.M., Galan, J.C., 2012. CTX-M Enzymes: Origin and Diffusion. Front Microbiol. 3, 110.

Carrico, J.A., Silva-Costa, C., Melo-Cristino, J., Pinto, F.R., de Lencastre, H., Almeida, J.S., Ramirez, M., 2006. Illustration of a common framework for relating multiple typing methods by application to macrolide-resistant Streptococcus pyogenes. Journal of clinical microbiology. 44, 2524-2532.

Clermont, O., Gordon, D., Denamur, E., 2015. A guide to the various phylogenetic classification schemes for Escherichia coli and the correspondence among schemes. Microbiology. 161, 980-988.

Cooper, J.E., Feil, E.J., 2004. Multilocus sequence typing--what is resolved? Trends Microbiol. $12,373-377$.

Dan, T., Liu, W., Sun, Z., Lv, Q., Xu, H., Song, Y., Zhang, H., 2014. A novel multi-locus sequence typing (MLST) protocol for Leuconostoc lactis isolates from traditional dairy products in China and Mongolia. BMC Microbiol. 14, 150. 
Davis, M.A., Sischo, W.M., Jones, L.P., Moore, D.A., Ahmed, S., Short, D.M., Besser, T.E., 2015. Recent emergence of $E$. coli carrying bla ${ }_{\mathrm{CTX}-\mathrm{M}}$ encoded cephalosporin resistance on Washington State dairy farms. Applied and environmental microbiology. 81, 4403-4410.

Doi, Y., Paterson, D.L., Egea, P., Pascual, A., Lopez-Cerero, L., Navarro, M.D., Adams-Haduch, J.M., Qureshi, Z.A., Sidjabat, H.E., Rodriguez-Bano, J., 2010. Extended-spectrum and CMY-type beta-lactamase-producing Escherichia coli in clinical samples and retail meat from Pittsburgh, USA and Seville, Spain. Clinical microbiology and infection : the official publication of the European Society of Clinical Microbiology and Infectious Diseases. 16, 33-38.

Edelstein, M., Pimkin, M., Palagin, I., Edelstein, I., Stratchounski, L., 2003. Prevalence and molecular epidemiology of CTX-M extended-spectrum beta-lactamase-producing Escherichia coli and Klebsiella pneumoniae in Russian hospitals. Antimicrob Agents Chemother. 47, 3724-3732.

Gilmour, M.W., Graham, M., Reimer, A., Van Domselaar, G., 2013. Public health genomics and the new molecular epidemiology of bacterial pathogens. Public Health Genomics. 16, 25 30.

Jolley, K.A., Maiden, M.C., 2014. Using MLST to study bacterial variation: prospects in the genomic era. Future Microbiol. 9, 623-630.

Kaper, J.B., Nataro, J.P., Mobley, H.L., 2004. Pathogenic Escherichia coli. Nat Rev Microbiol. 2, 123-140.

Livermore, D.M., 2012. Current epidemiology and growing resistance of gram-negative pathogens. Korean J Intern Med. 27, 128-142.

Maiden, M.C., 2006. Multilocus sequence typing of bacteria. Annu Rev Microbiol. 60, 561-588. 
Mollenkopf, D.F., Weeman, M.F., Daniels, J.B., Abley, M.J., Mathews, J.L., Gebreyes, W.A., Wittum, T.E., 2012. Variable within- and between-herd diversity of CTX-M cephalosporinase-bearing Escherichia coli isolates from dairy cattle. Appl Environ Microbiol. 78, 4552-4560.

Nicolas-Chanoine, M.H., Blanco, J., Leflon-Guibout, V., Demarty, R., Alonso, M.P., Canica, M.M., Park, Y.J., Lavigne, J.P., Pitout, J., Johnson, J.R., 2008. Intercontinental emergence of Escherichia coli clone O25:H4-ST131 producing CTX-M-15. J Antimicrob Chemother. 61, 273-281.

Overdevest, I.T., Heck, M., van der Zwaluw, K., Willemsen, I., van de Ven, J., Verhulst, C., Kluytmans, J.A., 2012. Comparison of SpectraCell RA typing and multilocus sequence typing for extended-spectrum-beta-lactamase-producing Escherichia coli. J Clin Microbiol. 50, 3999-4001.

Paul, S., Linardopoulou, E.V., Billig, M., Tchesnokova, V., Price, L.B., Johnson, J.R., Chattopadhyay, S., Sokurenko, E.V., 2013. Role of homologous recombination in adaptive diversification of extraintestinal Escherichia coli. J Bacteriol. 195, 231-242.

Peirano, G., Pitout, J.D., 2010. Molecular epidemiology of Escherichia coli producing CTX-M beta-lactamases: the worldwide emergence of clone ST131 O25:H4. Int J Antimicrob Agents. 35, 316-321.

Pitout, J.D., Laupland, K.B., 2008. Extended-spectrum beta-lactamase-producing Enterobacteriaceae: an emerging public-health concern. Lancet Infect Dis. 8, 159-166.

Schwartz, D.J., Kalas, V., Pinkner, J.S., Chen, S.L., Spaulding, C.N., Dodson, K.W., Hultgren, S.J., 2013. Positively selected FimH residues enhance virulence during urinary tract infection by altering FimH conformation. Proc Natl Acad Sci U S A. 110, 15530-15537. 
Severiano, A., Pinto, F.R., Ramirez, M., Carrico, J.A., 2011. Adjusted Wallace coefficient as a measure of congruence between typing methods. J Clin Microbiol. 49, 3997-4000.

Simpson, E.H., 1949. Measurement of species diverity. Nature. 163, 688.

Sokurenko, E.V., Chesnokova, V., Dykhuizen, D.E., Ofek, I., Wu, X.R., Krogfelt, K.A., Struve, C., Schembri, M.A., Hasty, D.L., 1998. Pathogenic adaptation of Escherichia coli by natural variation of the FimH adhesin. Proc Natl Acad Sci U S A. 95, 8922-8926.

Toval, F., Kohler, C.D., Vogel, U., Wagenlehner, F., Mellmann, A., Fruth, A., Schmidt, M.A., Karch, H., Bielaszewska, M., Dobrindt, U., 2014. Characterization of Escherichia coli isolates from hospital inpatients or outpatients with urinary tract infection. J Clin Microbiol. 52, 407-418.

Urwin, R., Maiden, M.C., 2003. Multi-locus sequence typing: a tool for global epidemiology. Trends Microbiol. 11, 479-487.

van Belkum, A., Tassios, P.T., Dijkshoorn, L., Haeggman, S., Cookson, B., Fry, N.K., Fussing, V., Green, J., Feil, E., Gerner-Smidt, P., Brisse, S., Struelens, M., 2007. Guidelines for the validation and application of typing methods for use in bacterial epidemiology. Clin Microbiol Inf. 13 Suppl 3, 1-46.

Weissman, S.J., Chattopadhyay, S., Aprikian, P., Obata-Yasuoka, M., Yarova-Yarovaya, Y., Stapleton, A., Ba-Thein, W., Dykhuizen, D., Johnson, J.R., Sokurenko, E.V., 2006. Clonal analysis reveals high rate of structural mutations in fimbrial adhesins of extraintestinal pathogenic Escherichia coli. Mol Microbiol. 59, 975-988.

Weissman, S.J., Johnson, J.R., Tchesnokova, V., Billig, M., Dykhuizen, D., Riddell, K., Rogers, P., Qin, X., Butler-Wu, S., Cookson, B.T., Fang, F.C., Scholes, D., Chattopadhyay, S., 
Sokurenko, E., 2012. High-resolution two-locus clonal typing of extraintestinal pathogenic Escherichia coli. Appl Environ Microbiol. 78, 1353-1360.

321 Wirth, T., Falush, D., Lan, R., Colles, F., Mensa, P., Wieler, L.H., Karch, H., Reeves, P.R.,

322 Maiden, M.C., Ochman, H., Achtman, M., 2006. Sex and virulence in Escherichia coli: an evolutionary perspective. Mol Microbiol. 60, 1136-1151.

324 Zhang, J., Kong, Y., Ruan, Z., Huang, J., Song, T., Song, J., Jiang, Y., Yu, Y., Xie, X., 2014. Correlation between Ureaplasma subgroup 2 and genitourinary tract disease outcomes revealed by an expanded multilocus sequence typing (eMLST) scheme. PLoS One. 9, e104347. 